\title{
Is all we know that we know nothing? A critical review of the prevalence of somatoform disorders in the elderly
}

\author{
Maria Christina Dehoust ${ }^{1}$, Holger Schulz ${ }^{1}$, Martin Härter ${ }^{1}$, Sylke Andreas ${ }^{1,2}$ \\ ${ }^{1}$ Department of Medical Psychology, University Medical Centre Hamburg-Eppendorf, Hamburg, Germany \\ ${ }^{2}$ Institute for Psychology, Alpen-Adria Universität Klagenfurt, Klagenfurt, Austria \\ Email: m.dehoust@uke.de
}

Received 3 June 2013; revised 2 July 2013; accepted 10 July 2013

Copyright (c) 2013 Maria Christina Dehoust et al. This is an open access article distributed under the Creative Commons Attribution License, which permits unrestricted use, distribution, and reproduction in any medium, provided the original work is properly cited.

\begin{abstract}
Objective: As noted in previous reviews, the prevalence rates for somatoform disorders in the elderly that have been reported are highly heterogeneous. The main aim of this paper is to identify the reasons for the substantial variation in prevalence rates and discuss the potential of future diagnostic criteria to address current difficulties. Methods: We conducted a selective review of the literature on the prevalence of somatoform disorders in elderly populations. Results: We found significant conceptual differences between the described diagnostic groups and the criteria applied across studies. Moreover, substantial disparities related to sample selection, age cut-offs, and applied measures were revealed. Conclusions: A general conceptual confusion exists throughout the literature regarding somatoform disorders in the elderly that significantly hinder the comparison and integration of results and can lead to premature conclusions. The redefinition of the somatoform disorder category in the next version of the DSM should be taken as an opportunity to address this issue and facilitate research.
\end{abstract}

Keywords: Somatoform Disorders; Epidemiology; Diagnostics; DSM-V; Geriatrics

\section{INTRODUCTION}

Although somatoform disorders are considered to be one of the most common mental disorders in primary care settings [1], they are the focus of substantially less empirical research than affective or anxiety disorders [2]. This divergence between clinical impressions and research findings has stimulated continuous debates about the basic assumptions surrounding the interplay of mind and body, etiological models, diagnostics and treatment modalities. Due to demographic changes, this discussion also needs to integrate the special characteristics with requirements of elderly patients. Currently, however, little is known about the relation between age and somatoform disorders. Important population based studies that have investigated the prevalence of mental disorders define the age of 65 years as a cutoff and thereby exclude the elderly population [3-6] or somatoform disorders are excluded a priori in studies exploring mental disorders in the elderly [7]. Some attention has already been paid to the neglect of somatoform disorders by geriatric psychiatry [8], yet the reviews dealing with this issue all come to similar conclusions: empirical data are scarce, and results are highly heterogeneous, as 12 month prevalence rates vary from $0.0 \%$ to $30.1 \%$ [9-11].

At the same time, the neglect of somatoform disorders in epidemiological studies is not specific to elderly populations [12]. One main reason for this omission is the lack of suitable diagnostic criteria that allow for valid assessments and evaluations of somatoform disorders [13]. The phenomenon of patients reporting somatic symptoms that are not well explained by general medical conditions has been difficult to name and conceptualize, and diagnostic classification of somatoform disorders is thus a challenging task [14]. The basic principle being the assessment of somatoform disorders is subject to a rather antiquated mind/body dualism that requires a stringent differentiation between medically unexplained and explained symptoms. This main source of criticism has been addressed in a number of studies [e.g.,15-19], and among others, this criticism has led to the proposal of a drastic reorganization of the somatoform disorder cluster in the next revision of the Diagnostic and Statistical Manual of Mental Disorders [20]. It is our view that the validity of this proposal should also be evaluated and discussed with regard to the increasing number of elderly patients. 
To explore reasons for the enduring and dissatisfying state of research concerning prevalence estimates of somatoform disorders in the elderly and to illustrate the possible remedies changes in the diagnostic classifications could produce, we reviewed the research literature surrounding the following two questions:

1) What are the main reasons for the heterogeneous findings regarding prevalence rates of somatoform disorders in the elderly?

2) Can the DSM-V facilitate research and clinical management of somatoform disorders in the elderly?

To facilitate understanding of the difficulties associated with the diagnosis of somatoform disorders, we briefly illustrate the historical development of this controversial group of disorders and describe the current diagnostic criteria.

\section{A BRIEF HISTORICAL CONSIDERATION}

First described by the Austrian physician and psychoanalyst Wilhelm Stekel in 1922, the phenomenon of somatization has been a fascinating and debate-stimulating field of clinical psychology ever since. The concept was originally termed "Organsprache” by Stekel, which literally means "organ speech”, a vague concept introduced by him to illustrate psychological conflict expressed as physical symptoms [21]. The translator of Stekels' book used another term, somatization, which would become an ubiquitous label for many different conditions [22]. Originally meant to describe a psychological mechanism, somatization was soon also used to describe the symptoms caused by this mechanism, and this resulted in lasting uncertainty surrounding the whole concept.

In addition to the concept of somatization, another phenomenon, namely hysteria, played a major role in the development of the latter conceptualization of somatoform disorders. In 1859, Pierre Briquet published his comprehensive clinical and epidemiological study of 430 patients suffering from hysteria in which he emphasized the polysymptomatic nature of the disease and its protracted timecourse [23]. In contrast, some years later, Jean-Martin Charcot gave importance to a monosymptomatic manifestation and claimed hysteria was a neurological disorder to which patients were pre-disposed by hereditary features of their nervous system [24]. Inspired by the work of Charcot, Breuer and Freud in 1893 formulated the first psychoanalytic approach to explaining the phenomenon of hysteria. They introduced the term conversion to describe the substitution of a somatic symptom for a repressed idea [25]. The latter formulation of conversion disorder was derived from this concept, whereas the latter formulation of somatization disorder was derived from Briquets' polysymptomatic hysteria concept and, as such, it was also known for a long time as "Briquet-Syndrome".

In the first edition of the Diagnostic and Statistical Manual of Mental Disorders (DSM) published by the American Psychiatric Association [26], conversion disorder appeared as “conversion reaction”. In the subsequent version, conversion disorder was clustered with dissociation disorder under the new diagnostic category of "hysterical neurosis" [27]. However, this category was dropped in the next edition of the DSM, which was published in 1980. The emphasis on clinical phenomenology rather than etiology led to a return to Briquet's elaborate description of a polysymptomatic chronic condition, which was introduced as "somatization disorder" in DSM-III and became the key diagnosis of the "somatoform disorder" group [28]. The category also included “conversion disorder" "hypochondriasis”, “psychogenic pain disorder" and the residual category "atypical somatoform disorder".

In the latest revision, some minor changes were made such as dropping psychogenic from pain disorder, renaming atypical somatoform disorder as "somatoform disorder not otherwise specified" and adding "body dysmorphic disorder”. Current diagnostic criteria for somatization disorder and pain disorder according to DSM IV are displayed in Table 1. Whenever a patient does not meet all of the specific symptomatic criteria for somatization disorder (i.e., 4 pain, 2 gastrointestinal, 1 sexual, 1 pseudoneurological symptom) but suffers from at least 1 medically unexplained symptom for at least 6 months, he will be diagnosed with "undifferentiated somatoform disorder". This category was introduced to catch those patients who do not fulfill the criteria for somatization disorder but appear to be clearly ill [29]. This rather cumbersome category turned out to be more prevalent than other primary disorders within the cluster [30,31].

\section{PREVALENCE OF SOMATOFORM DISORDERS IN THE ELDERLY-WHY WE SHOULD NOT DRAW HASTY CONCLUSIONS}

As mentioned previously, studies investigating somatoform disorders in the elderly are rare, and the reported prevalence rates are highly heterogeneous $[9,11]$. One reason for this heterogeneity might lie in the controversial conceptualization of this group of disorders. To explore this hypothesis in more detail, we reviewed the literature with an emphasis on the described diagnostic groups and applied criteria. Moreover, we also looked for other factors that may account for the heterogeneity such as sample selection, age cut-offs, and applied measures. We focused our evaluation on studies that have been included in previous literature reviews because these studies are likely of sufficient quality to draw 
Table 1. DSM-IV criteria for somatization and pain disorder (29).

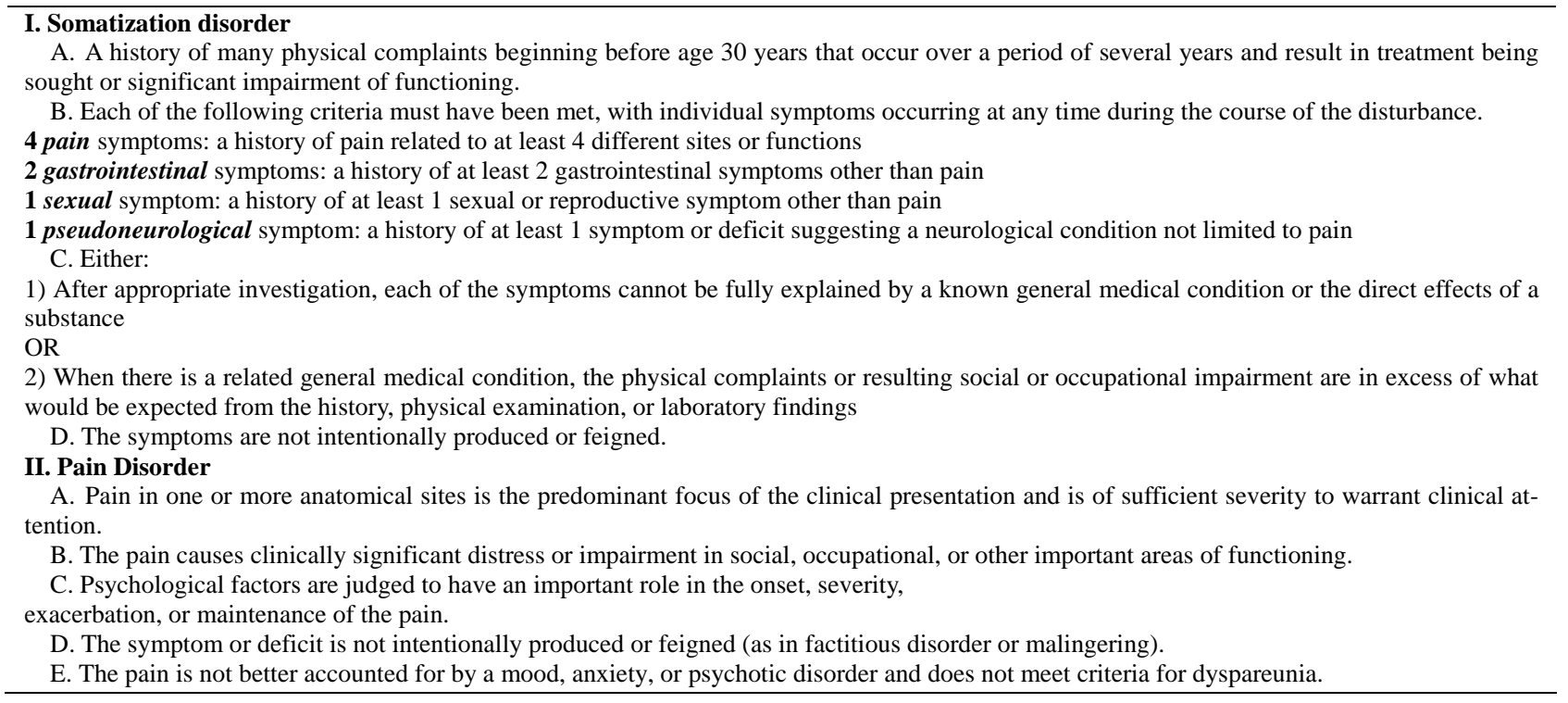

general conclusions about somatoform disorders in the elderly. An initial search yielded 4 review articles, of which one was excluded for language reasons [10] and one because no systematic literature search had been performed [8]. This procedure led to the selection of two systematic reviews [9,11] resulting in 16 potentially relevant epidemiological studies (see Table 2). Examining these studies in more detail led us to believe that that no valid conclusions can be drawn about the prevalence of somatization and hypochondriasis in elderly people for several reasons including counterintuitive age cutoffs, diverse samples, inconsistent measures and, most notably, heterogeneous diagnostic groups.

1) Counterintuitive age cut-offs

In 7 of the 16 studies included in previous reviews, the age spans referred to as elderly did not correspond with the conventionally defined span of the aged population [32]. The cut-off was set at 45 years of age in three studies [33-35] and at $50[3,36], 55$ [37] or 57 [38] in the remaining studies.

2) Diverse samples

Of the evaluated studies, 10 investigated somatoform disorders within the general population [3,33-36,38-42], and 5 studies were conducted in primary care settings [43-47]. The validity of the results from those studies is limited to older treatment-seeking samples, which can differ from community-based samples, and therefore, studies of treatment-seeking and community-based samples should be interpreted independently. Another included study reported a prevalence rate of $36.1 \%$ for DSM-III-R somatization disorder in those 55 years or older, which noticeably exceeds all the other rates reported [37]. However, the sample consisted solely of women attending primary and secondary care clinics.
This study might therefore be relevant in terms of age relations within clinical samples but does not allow for any assumptions about prevalence.

3) Inconsistent measures

The applied assessment tools differ across the studies and include self-report measures [34,38], semi-structured interviews of assured psychometric properties $[40,43,46]$, newly self-developed interviews $[37,39,42]$ and analyses of electronic routine medical records [47]. At least 7 studies used fully structured interviews, and the Composite International Diagnostic Interview (CIDI) was deployed in 5 of the studies $[3,35,36,44,48]$. However, different versions and different time-windows also impede the comparability of results in this case.

4) Heterogeneous diagnostic groups

In addition to all the previously mentioned differences in study populations and measures, significant differences across studies between described diagnostic groups are especially striking. For example, 5 of the studies listed in Table 2 did not use DSM or ICD criteria. Stenback et al. [42] identified "hypochondria or hypochondria-like concerns" in $13.7 \%$ of their sample, Larkin et al. [40] reported a prevalence rate of $0.4 \%$ for "hypochondriacal neurosis”, Costa and McCrae [38] could not find any relation between age and "somatic complaints" and Verhaak et al. [47] reported a prevalence of $4.6 \%$ for "medically unexplained symptoms" that were defined by the absence of a diagnosis and the frequency of doctor visits (at least 4 contacts) in routine patient records. Hardy et al. [39] reported a prevalence rate of $13 \%$ for "medical somatoform disorders" using criteria that were identical to those for undifferentiated somatoform disorder according to the DSM-IV except without consideration of the E-criterion, which necessitates the exclusion 
Table 2. Epidemiological studies of somatization in the elderly considered in previous reviews.

\begin{tabular}{|c|c|c|c|c|c|c|}
\hline Study & $\mathbf{N}$ & Age cut off & Crieria measures & Time-window & Described diagnostic group & Prevalence \\
\hline \multicolumn{7}{|c|}{ General population } \\
\hline Stenback 1978 & 106 & 70 & semistructured interview & ns & hypochondria/hypochondria like concern & $13.7 \%$ \\
\hline Costa 1980 & 1038 & 57 & self-report symptom checklist & ns & any somatic complaints & $\mathrm{ns}^{1}$ \\
\hline Escobar 1987 & 3132 & 45 & DIS & lifetime & somatization disorder (DSM III) & $0.1 \%$ \\
\hline Larkin 1992 & 1070 & 65 & GMS & 12 months & hypochondriacal neurosis & $0.5 \%$ \\
\hline Wittchen 1992 & 188 & 45 & CIDI & 6 months & any somatofrom disorder (DSM IV) & $1 \%$ \\
\hline$\underline{\text { Hardy } 1995}$ & 504 & 65 & semistructured interview & 12 months & medical somatoform disorder & $13 \%$ \\
\hline$\underline{\text { Hiller } 2006}$ & 1312 & 45 & SOMS-2 & 1 week & current somatization & $26.8 \%$ \\
\hline \multirow{4}{*}{ Leikens 2007} & \multirow{4}{*}{163} & \multirow{4}{*}{66} & \multirow{4}{*}{ CIDI } & 6 months & multisomatoform disorder & $9.8 \%$ \\
\hline & & & & 6 months & somatoform disorder not otherwise specified & $13.5 \%$ \\
\hline & & & & 6 months & current somatoform disorder & $18.4 \%$ \\
\hline & & & & 6 months & severe current somatoform disorder & $4.9 \%$ \\
\hline Jacobi 2004 & & 50 & CIDI & 12 months & any somatoform disorder (DSM IV) & $11.7 \%$ \\
\hline \multirow{2}{*}{ Fröhlich 2006} & \multirow{2}{*}{4181} & \multirow{2}{*}{50} & \multirow{2}{*}{ CIDI } & 12 months & somatoform pain disorder (DSM IV) & $8.6 \%$ \\
\hline & & & & 12 months & medically unexplained symptoms & $27.2 \%$ \\
\hline \multicolumn{7}{|c|}{ Primary care } \\
\hline Kirmayer 1996 & 685 & ns & DIS & ns & somatic symptom index & $\mathrm{ns}^{1}$ \\
\hline Gureje 1997 & 5438 & 45 & CIDI & ns & somatization disorder (ICD-10) & $\mathrm{ns}^{2}$ \\
\hline \multirow{2}{*}{ Lyness1999 } & \multirow{2}{*}{224} & \multirow{2}{*}{60} & \multirow{2}{*}{ SCID } & point prevalence & somatoform pain disorder & $1.3 \%$ \\
\hline & & & & point prevalence & body dysmorphic disorder & $0.5 \%$ \\
\hline De Waal 2004 & 70 & 65 & SCAN & 6 months & somatoform disorders (DSM-IV) & $5.4 \%$ \\
\hline Verhaak 2006 & 225013 & 65 & medical records & 12 months & medically unexplained symptoms & $4.6 \%$ \\
\hline \multicolumn{7}{|c|}{ Clinical populations } \\
\hline Pribor 1994 & 83 & 55 & semistructured interview & ns & any somatoform disorder & $39.9 \%$ \\
\hline
\end{tabular}

Note: ns = not specified, DIS = Diagnostic Interview Schedule; GMS = Geriatric Mental state; SOMS = Screening for Somatoform Symptoms; CIDI = Composite International Diagnostic Interview; SCID = Structured Clinical Interview for DSM-IV disorders; SCAN = Schedules for Clinical Assessment in Neuropsychiatry; ICD = International Classification of Diseases; ${ }^{1}$ no relation between symptoms and age; ${ }^{2}$ slightly increase in symptoms with age.

of any other mental disorder.

Even though they applied the fully structured Composite International Diagnostic Interview (CIDI), Leikens and colleagues [41] did not adhere to the standard diagnostic criteria according to the DSM-IV. They reported prevalence rates for "multisomatoform disorder (MSD)" and "somatoform disorder not otherwise specified (SDnos)" and left out other potentially relevant diagnostic subgroups of somatoform disorders such as somatization disorder, hypochondriasis and pain disorder. Instead, they introduced a new diagnostic category "severe current somatoform disorder”, which included MSD and SDnos with the addition of the DSM-IV impairment criterion (B-criterion). The prevalence rate of $27.2 \%$ for "medically unexplained symptoms" extracted from the study by Fröhlich et al. [2006] actually reflects the percentage of people suffering from at least one medically unexplained pain symptom; adding the DSM-IV impairment criterion (B-criterion) reduces the prevalence rate to 8.6\% [36]. This finding is also interesting with regard to the study by Jacobi et al. [3], which is based on the same sample (German Health Survey, GHS). Jacobi et al. [3] combined somatization disorder, undifferentiated somatization disorder, hypochondriasis, abridged somatization disorder according to Escobar [49] and pain disorder into the category of "any somatoform disorder" and reported a 12-month prevalence rate for this disorder group of $11.7 \%$ for those aged 50 to 65, but unfortunately no prevalence rates for the subtypes are reported. However, compared to the results by Fröhlich et al. [36], it becomes apparent that $8.6 \%$ of the disorders classified as "any somatoform disorders" are pain disorders and that the remaining $3.1 \%$ are distributed over the 4 above-mentioned subtypes. The reported prevalence rate of $4.3 \%$ for abridged somatization disorder for the whole GHS sample indicates that this might be the second most frequent disorder within the 50 to 65-year-old group. Unfortunately, no prevalence rates across the whole 
sample are given for somatization disorder, undifferentiated somatization disorder or hypochondriasis, but we can assume that those rates were close to zero.

The $26.8 \%$ prevalence reported for somatoform disorders in people older than 45 years in the study by Hiller et al. [34] clearly exceeds estimates of the other studies in the review. On the one hand, this might be because a questionnaire was used to assess somatoform symptoms; on the other hand, this might be because the criterion was suffering from at least one symptom with a self-rated severe or very severe degree of associated impairment. Again, this resembles the undifferentiated somatoform disorder and neglects all other diagnoses of the DSM-IV somatoform disorder cluster.

In addition to the limited number of studies and varying age-cut-offs, assessment tools, and study populations, a major difficulty in interpreting research findings regarding somatoform disorders in the elderly is the rather inconsistent utilization of diagnostic labels and criteria. Although the generic terms "somatoform disorders" and "medically unexplained symptoms" apply to all of the above-mentioned studies, none of these studies really reported prevalence rates for the same entity. This general conceptual confusion might be a result of inherent difficulties in the definition of diagnostic criteria, which significantly hinders the comparison and integration of results and can lead to premature conclusions. The redefinition of the somatoform disorder category in the next version of the DSM can be considered an attempt to address this issue and facilitate research.

\section{DSM-V SOMATIC SYMPTOM DISORDER-A HELPFUL SOLUTION?}

Current diagnostic criteria for somatoform disorders have met criticism for a number of reasons. First, the idea that symptoms can be reliably divided those with physical or psychological causes is theoretically questionable and not supported by empirical data [14,50,51]. Regarding somatization disorder, there is agreement that simple symptom counts are not sufficient to diagnose a mental disorder because they neglect psychological aspects of the disorder [52]. Moreover, the time criterion (onset before the age of 30) for this disorder has been considered to be too restrictive [53].

On closer inspection with regard to older patients, the current criteria seem to discriminate against this group in particular by impeding the diagnostic process and thereby adding to the risk of underestimations of prevalence. The question of how to handle comorbid medical conditions becomes more significant in a population in which being physically ill is the rule rather than the exception. Beside chronic physical illness, other age-related phenomena might be used by clinicians and also by patients themselves to explain non-specific somatic symptoms in the elderly [54]. These phenomena include, for example, general degenerative processes, a tendency to multimorbidity with increasing age, and frequent medication use, which can be accompanied by nonspecific side effects. Older people may also have difficulties in distinguishing symptoms from the background noise of the general somatic sensations they experience and might be more attached to biological models of illness and not take psychosocial factors into account as suggested by Wijerante and Hickie [55]. This separation of mind and body may lead to a neglect of accompanying psychological features that is further supported by clinicians who are also attached to a biomedical way of thinking. In addition to this major difficulty for defining medically unexplained symptoms, the current DSM-IV time criterion for somatization disorder requires that patients remember symptoms correctly over many years and that they also remember the time of onset, which needs to be before the age of 30 [29]. This lifetime recall is error-prone and might be an unnecessary challenge for elderly people suffering from current distress $[48,56]$.

As we have already mentioned, somatoform disorders as defined by the DSM-IV do not appear to form a coherent category, and many of the subcategories have failed to achieve the status of discrete psychiatric disorders $[13,18,56]$. This has led to the exclusion of somatoform disorders in major epidemiological surveys and to proposals of a number of alternative criteria, which has resulted in a range of subtypes of somatoform disorders with a rather confusing nomenclature. In the rationale for the suggested revision of the somatoform disorder category in the DSM-V, it is stated that the group considers that the current DSM-IV somatoform diagnoses (somatization disorder, somatoform disorder NOS, undifferentiated somatoform disorder, hypochondriasis and the pain disorders) are so flawed that complete restructuring of these diagnoses is required [57]. Within the scope of this restructuring, the previous subcategories will be integrated to a single diagnosis entitled "somatic symptom disorder”. Symptoms will no longer need to be medically unexplained, several affective, cognitive and behavioral aspects will be included, and the impact of the time criterion will be reduced (for a detailed description of proposed criteria see Table 3 ). In general, the new classification seems to be more appropriate for reliably diagnosing this type of mental disorder and more valid for ageing populations than its precursor. Addressing physical symptoms regardless of their etiology might facilitate the diagnostic process especially in symptom-burdened older patients $[58,59]$, and abolishment of the time criterion will contribute to a shift towards current suffering, which makes sense from a clinical point of view.

Voigt and colleagues [60] recently evaluated the new criteria in terms of clinical utility and construct, descrip- 
Table 3. APA proposal for the revision of the somatoform disorder category (57).

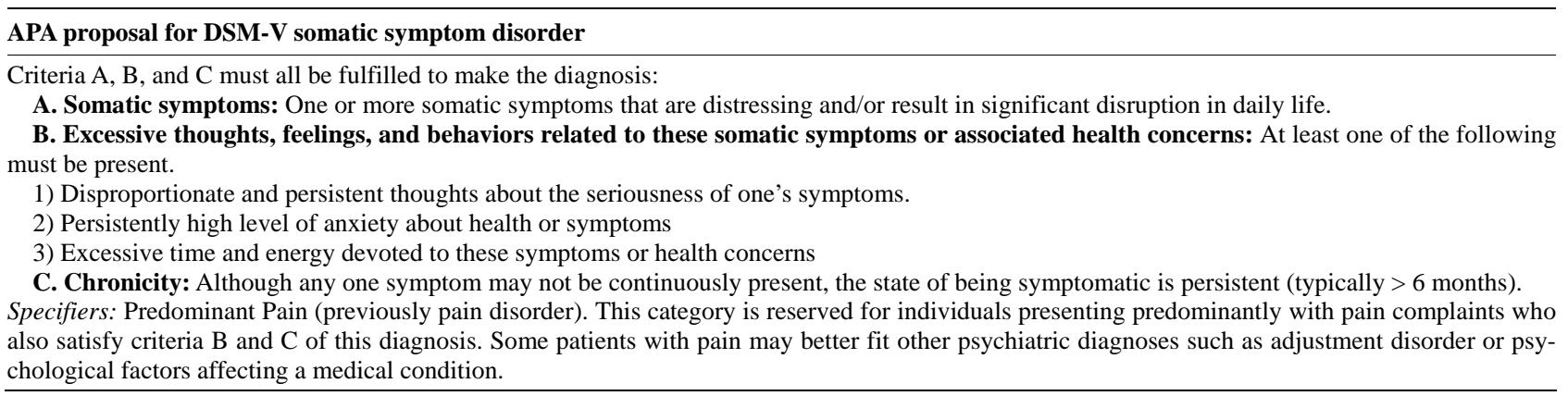

tive, and predictive validity and concluded the upcoming diagnostic classification of somatic symptom disorder will result in substantial improvement. This confidence is based mainly on the inclusion of positive criteria originating from a biopsychosocial model and the integration of a dimensional approach that reflects both somatic and psychological symptom severity. These major revisions can also be considered reasonable for the elderly population. The abolishment of high case thresholds is likely to facilitate detection of somatoform disorders in the elderly. Moreover, the inclusion of severity ratings and criteria that exceed simple symptom counts (i.e., cognitive, affective, and behavioral factors) allows for a more wideranging investigation of somatoform disorders that will include research on diversity and severity in elderly populations. This kind of studies might lead to a more accurate clinical description of the disorder, which could be used as a basis for treatment recommendations. Additionally, the proposal offers a uniform conceptualization that could reduce the band-width of subcategories subsumed under the term somatoform disorders and lead to increased comparability of research findings.

However, some doubt about the validity and utility of the new classification still remains. For example, no clear symptom threshold is provided, and specification about the assessment of psychological symptoms is lacking. Additionally, there is a need for further research on psychological and social factors that accompany somatoform disorders in the elderly (B criteria in DSM-V proposal). Evidence for the validity and clinical utility of the proposed cognitive, affective and behavioral criteria is based mainly on studies investigating somatoform disorders in adult populations [60], and it is questionable whether these findings can be adapted to the elderly, as the disorder may present differently in older people.

Although empirical data support the validity of the application of less restrictive criteria [49,50,61,62], the proposed abolishment of a defined symptom threshold bears the risk of overestimating somatoform symptoms. Overestimation may be especially problematic in elderly populations, as single somatoform symptoms are frequent $[34,36,41]$, and there is at least some evidence for an increased presentation of physical symptoms in older patients primarily suffering from other mental disorders such as anxiety [63,64] or depression [65-68].

\section{CONCLUSION}

Our review of the literature has made it apparent that somatoform complaint is a clinical relevant topic in the elderly; however, little is known about the prevalence and manifestation of this phenomenon, which hinders recommendations for assessment and treatment. To some extent, the limited empirical data on somatoform disorders in older people might be explained by the current diagnostic criteria, which offer several obstacles and have received much criticism. The need to rule out any medical explanation and the rigid time criterion (onset before the age of 30) particularly impedes the detection of clinically relevant somatoform syndromes in the elderly. Moreover, the inconsistent use of diagnostic labels and criteria in studies investigating somatoform disorders in elderly populations makes it difficult to draw valid conclusions about the size and burden of the problem. The proposed DSM-V criteria address this problem of inconsistence nomenclature by integrating several disorders into one entity, somatic symptom disorder. The suggested criteria for this diagnosis seem to be more agesensitive, but further research is certainly needed to answer the question of whether these new criteria will substantially improve the validity and practicability of diagnosing somatoform disorders in the elderly.

\section{REFERENCES}

[1] Hanel, G., Henningsen, P., Herzog, W., Sauer, N., Schaefert, R., Szecsenyi, J., et al. (2010) Depression, anxiety, and somatoform disorders: Vague or distinct categories in primary care? Results from a large cross-sectional study. Journal of Psychosomatic Research, 67, 189-197. http://dx.doi.org/10.1016/j.jpsychores.2009.04.013

[2] Witthöft, M. and Hiller, W. (2010) Psychological approaches to origins and treatments of somatoform disorders. Annual Review of Clinical Psychology, 6, 257-283. http://dx.doi.org/10.1146/annurev.clinpsy.121208.131505 
[3] Jacobi, F., Wittchen, H., Hölting, C., Höfler, M., Pfister, H., Müller, N., et al. (2004) Prevalence, co-morbidity and correlates of mental disorders in the general population: Results from the german health interview and examination survey (GHS). Psychological Medicine, 54, 597-611. http://dx.doi.org/10.1017/S0033291703001399

[4] Meyer, C., Rumpf, H., Hapke, U., Dilling, H. and John, U. (2000) Lifetime prevalence of mental disorders in the adult general population: Findings from the TACOS study. Der Nervenarzt, 71, 535-542. http://dx.doi.org/10.1007/s001150050623

[5] Canino, G.J., Bird, H.R., Shrout, P.E., Rubio-Stipec, M., Bravo, M., Martinez, R., et al. (1987) The prevalence of specific psychiatric disorders in Puerto Rico. Archives of General Psychiatry, 44, 727-735. http://dx.doi.org/10.1001/archpsyc.1987.0180020005300 $\underline{8}$

[6] Wells, J.E., Bushnell, J.A., Hornblow, A.R., Joyce, P.R. and Oakley-Browne, M.A. (1989) Christchurch epidemiology study: Part I. Methodology and lifetime prevalence for specific psychiatric disorders. Australian \& New Zealand Journal of Psychiatry, 23, 315-326. http://dx.doi.org/10.3109/00048678909068289

[7] Helmchen, H., Baltes, M., Geiselmann, B., Kanowski, S., Linden, M., Reischies, F., et al. (1996) Psychische erkrankungen im alter. In: Mayer, K. and Baltes, P., Eds., Die Berliner Alterstudie, Akademie Verlag, Berlin, 185220.

[8] Wijeratne, C., Brodaty, H. and Hickie, J. (2003) The neglect of somatoform disorders by old age psychiatry: Some explanations and suggestions for future research. International Journal of Geriatric Psychiatry, 18, 812819. http://dx.doi.org/10.1002/gps.925

[9] Hilderink, P., Collard, R., Rosmalen, J. and OudeVoshaar, R. (2013) Prevalence of somatoform disorders and medically unexplained symptoms in old age populations in comparison with younger age groups: A systematic review. Ageing Research Reviews, 12, 151-156. http://dx.doi.org/10.1016/j.arr.2012.04.004

[10] Schneider, G. and Heuft, G. (2011) Organisch nicht erklärbare somatoforme Beschwerden und Störungen im Alter: Ein systematischer Literaturüberblick [Medically unexplained and somatoform complaints and disorders in the elderly: A systematic review of the literature]. Zeitschrift fur Psychosomatische Medizin und Psychotherapie, 57, 1438-3608.

http://www.V-r.de/en/magazine_edition-0-0/zeitschrift_fu er psychosomatische medizin und psychotherapie 201 1_57_4-1009303/

[11] Sheehan, B. and Banerjee, S. (1999) Review: Somatization in the elderly. International Journal of Geriatric Psychiatry, 14, 1044-1049.

http://dx.doi.org/10.1002/(SICI)1099-1166(199912)14:12 $<1044:$ :AID-GPS55>3.0.CO;2-0

[12] Wittchen, H.U. (2004) Continued needs for epidemiological studies of mental disorders in the community. Psychotherapy and Psychosomatics, 73, 197-206. http://dx.doi.org/10.1159/000077738

[13] Creed, F. and Barsky, A. (2004) A systematic review of the epidemiology of somatisation disorder and hypochondriasis. Journal of Psychosomatic Research, 56, 391408. http://dx.doi.org/10.1016/S0022-3999(03)00622-6

[14] Sharpe, M. and Carson, A.J. (2001) “Unexplained” somatic symptoms, functional syndromes, and somatization: Do we need a paradigm shift? Annals of Internal Medicine, 134, 926-930.

http://dx.doi.org/10.7326/0003-4819-134-9_Part_2-20010 $\underline{5011-00018}$

[15] Creed, F. (2006) Can DSM-V facilitate productive research into the somatoform disorders? Journal of Psychosomatic Research, 60, 331-334.

http://dx.doi.org/10.1016/j.jpsychores.2006.02.007

[16] Janca, A. (2005) Rethinking somatoform disorders. Current Opinion in Psychiatry, 18, 65-71.

[17] Löwe, B., Mundt, M., Herzog, W., Brunner, R., Backenstrass, M., Kronmüller, K., et al. (2008) Validity of current somatoform disorder diagnoses: Perspectives for classification in DSM-V and ICD-11. Psychopathology, 41, 4-9. http://dx.doi.org/10.1159/000109949

[18] Mayou, R., Kirmayer, L.J., Simon, G., Kroenke, K. and Sharpe, M. (2005) Somatoform disorders: Time for a new approach in DSM-V. American Journal of Psychiatry, 162, 847-855. http://dx.doi.org/10.1176/appi.ajp.162.5.847

[19] Rief, W. and Hiller, W. (1999) Toward empirically based criteria for the classification of somatoform disorders. Journal of Psychosomatic Research, 46, 507-518. http://dx.doi.org/10.1016/S0022-3999(99)00023-9

[20] Dimsdale, J. and Creed, F. (2009) The proposed diagnosis of somatic symptom disorders in DSM-V to replace somatoform disorders in DSM-IV-A preliminary report. Journal of Psychosomatic Research, 66, 473-476. http://dx.doi.org/10.1016/j.jpsychores.2009.03.005

[21] Stekel, W. (1922) Impulshandlungen, wandertrieb, dipsomanie, kleptomanie, pyromanie und verwandte zustände: Störungen des trieb- und affektlebens. Urban und Schwarzenberg, Berlin.

[22] van Teslaar, J.S. and Stekel, W. (1925) Peculiarities of behavior: Wandering mania, dipsomania, cleptomania, pyromania and allied impulsive acts. William and Norgate, London.

[23] Briquet, P. (1859) Traite de l'hysterie. Bailliere et Fils, Paris.

[24] Charcot, J.M. (1872) Lecon sur le maladies du systeme nerveux faites a la Salpetiere. Delahaye, Paris.

[25] Breuer, J. and Freud, S. (1893) Über den psychischen Mechanismus hysterischer Phänomene. Vorläufige Mitteilung. Neurologisches Centralblatt, 12, 4-10.

[26] APA (1952) Diagnostic and statistical manual of mental disorders. American Psychiatric Association Washington DC.

[27] APA (1968) Diagnostic and statistical manual of mental disorders (2nd Edition) (DSM-II). American Psychiatric Association Washington DC.

[28] APA (1980) Diagnostic and statistical manual of mental 
disorders (3rd Edition) (DSM-III). American Psychiatric As- sociation, Washington DC.

[29] APA (1994) Diagnostic and statistical manual of mental disorders (4th edition) (DSM-IV). American Psychiatric Association, Washington DC.

[30] Grabe, H.J., Meyer, C., Hapke, U., Rumpf, H., Freyberger, H., Dilling, H., et al. (2003) Specific somatoform disorders in the general population. Psychosomatics, 44, 304-311. http://dx.doi.org/10.1176/appi.psy.44.4.304

[31] Lynch, D.J., McGardy, A., Nagel, R. and Zsembik, C. (1999) Somatization in family practice: Comparing 5 methods of classification. The Primary Care Companion -Journal of Clinical Psychiatry, 1, 85-89. http://dx.doi.org/10.4088/PCC.v01n0305

[32] Roebuck, J. (1979) When does old age begin? Journal of Social History, 12, 16-28. http://dx.doi.org/10.1353/jsh/12.3.416

[33] Escobar, J.I., Burnam, M.A., Karno, M., Forsythe, A. and Golding, J.M. (1987) Somatization in the community. Archives of General Psychiatry, 44, 713-718. http://dx.doi.org/10.1001/archpsyc.1987.0180020003900 $\underline{6}$

[34] Hiller, W., Rief, W. and Braehler, E. (2006) Somatization in the population: From mild body misperceptions to disabling symptoms. Social Psychiatry and Psychiatric Epidemiology, 41, 704-712. http://dx.doi.org/10.1007/s00127-006-0082-y

[35] Wittchen, U., Essau, L.A., Von Zerssen, D., Kreig, J.-C. and Zaudig, M. (1992) Lifetime and six-month prevalence of mental disorders in the Munich follow-up study. Psychiatry and Clinical Neurosciences, 241, 247-258. http://dx.doi.org/10.1007/BF02190261

[36] Fröhlich, C., Jacobi, F. and Wittchen, H.U. (2006) DSMIV pain disorder in the general population. An ex- ploration of the structure and threshold of medically un- explained pain symptoms. European Archives of Psychiatry and Clinical Neuroscience, 256, 187-196. http://dx.doi.org/10.1007/s00406-005-0625-3

[37] Pribor, E.F., Smith, D.S. and Yutzy, S.H. (1994) Somatization disorder in elderly patients. The American Journal of Geriatric Psychiatry, 2, 109-117. http://dx.doi.org/10.1097/00019442-199405000-00004

[38] Costa, P.T. and McCrae, R.R. (1980) Somatic complaints in males as a function of age and neuroticism: A longitudinal analysis. Journal of Behavioral Medicine, 3, 245257. http://dx.doi.org/10.1007/BF00845050

[39] Hardy, P. (1995) Épidémiologie des troubles somatoformmes dans la population générale francais. L'Encéphale, 21, 191-199.

[40] Larkin, B.A., Copeland, J.R.M., Dewey, M.E., Davidson, I.A., Saunders, P.A. and Sharma, V.K., et al. (1992) The natural history of neurotic disorder in an elderly urban population. The British Journal of Psychiatry, 160, 681686. http://dx.doi.org/10.1192/bjp.160.5.681

[41] Leikens, K.A., Finset, A., Monum, T. and Sandanger, I. (2007) Current somatoform disorders in Norway: Prevalence, risk factors and comorbidity with anxiety, depresssion and musculoskeletal disorders. Social Psychiatry and
Psychiatric Epidemiology, 42, 698-710. http://dx.doi.org/10.1007/s00127-007-0218-8

[42] Stenback, A., Kumpulainen, M., Vauhkonen, M.-L. (1978) Illness and health behavior in septuagenarians. Journal of Gerontology, 33, 57-61.

[43] de Waal, M.W., Arnold, I.A., Eekhof, J.A. and van Hemert, A.M. (2004) Somatoform disorders in general practice: Prevalence, functional impairment and comorbidity with anxiety and depressive disorders. The British Journal of Psychiatry, 184, 470-476. http://dx.doi.org/10.1192/bjp.184.6.470

[44] Gureje, O., Simon, G.E., Ustun, T.B. and Goldberg, D.P. (1997) Somatization in cross-cultural perspective: A World Health Organization study in primary care. The American Journal of Psychiatry, 154, 989-995.

[45] Kirmayer, L.J. and Robbins, J.M. (1996) Patients who somatize in primary care: A longitudinal study of cognitive and social characteristics. Psychological Medicine, 26, 937-951. http://dx.doi.org/10.1017/S0033291700035273

[46] Lyness, J.M., Caine, E.D., King, D.A., Cox, C. and Yoediono, Z. (1999) Psychiatric disorders in older primary care patients. Journal of General Internal Medicine, 14, 249-254 http://dx.doi.org/10.1046/j.1525-1497.1999.00326.x

[47] Verhaak, P.F., Meijer, S.A., Visser, A.P. and Wolters, G. (2006) Persistent presentation of medically unexplained symptoms in general practice. Family Practice, 23, 414-420. http://dx.doi.org/10.1093/fampra/cml016

[48] Leiknes, K.A., Finset, A., Moum, T. and Sandanger, I. (2006) Methodological issues concerning lifetime medically unexplained and medically explained symptoms of the composite international diagnostic interview: A prospective 11-year follow-up study. Journal of Psychosomatic Research, 61, 169-179.

http://dx.doi.org/10.1016/j.jpsychores.2006.01.007

[49] Escobar, J.I., Rubio-Stipec, M., Canino, G. and Karno, M. (1989) Somatic symptoms index (SSI): A new and abridged somatization construct. Prevalence and epidemiological correlates in two large community samples. Journal of Nervous \& Mental Disease, 177, 140-146. http://dx.doi.org/10.1097/00005053-198903000-00003

[50] Escobar, J.I., Cook, B., Chen, C.N., Gara, M.A., Alegria, M. and Interian, A., et al. (2010) Whether medically unexplained or not, three or more concurrent somatic symptoms predict psychopathology and service use in community populations. Journal of Psychosomatic Research, 69, 1-8. http://dx.doi.org/10.1016/j.jpsychores.2010.01.001

[51] Ogden, J. (2003) What do symptoms mean. British Medical Journal, 327, 409-410. http://dx.doi.org/10.1136/bmj.327.7412.409

[52] Rief, W. and Isaac, M. (2007) Are somatoform disorders "mental disorders"? A contribution to the current debate. Current Opinion in Psychiatry, 20, 143-146. http://dx.doi.org/10.1097/YCO.0b013e3280346999

[53] Fink, P., Rosendal, M. and Olesen, F. (2005) Classification of somatization and functional somatic symptoms in primary care. Australian \& New Zealand Journal of Psychiatry, 39, 772-781. 
http://dx.doi.org/10.1080/j.1440-1614.2005.01682.x

[54] Sheehan, B., Philpot, M. and Banerjee, S. (2002) Attributions of physical symptoms in patients of an old age psychiatry service. International Journal of Geriatric Psychiatry, 17, 61-64. http://dx.doi.org/10.1002/gps.520

[55] Wijeratne, C. and Hickie, I. (2001) Somatic distress symptoms in later life: The need for paradigm change. Psychological Medicine, 31, 571-576. http://dx.doi.org/10.1017/S003329170100383X

[56] Simon, G.E. and Gureje, O. (1999) Stability of somatization disorder and somatization symptoms among primary care patients. Archives of General Psychiatry, 56, 90-95. http://dx.doi.org/10.1001/archpsyc.56.1.90

[57] APA. (2012) DSM-5 Development. Proposed RevisionsSomatic Symptom Disorder. http://www.dsm5.org/ProposedRevision/Pages/proposedr evision.aspx?rid=368\#.

[58] Mailis-Gagnon, A., Nicholson, K., Yegneswaran B. and Zurowski, M. (2008) Pain characteristics of adults 65 years of age and older referred to a tertiary care pain clinic. Pain Research \& Management, 13, 389-394.

[59] Wijeratne, C., Shome, S., Hickie, I. and Koschera, A. (2001) An age-based comparison of chronic pain clinic patients. International Journal of Geriatric Psychiatry, 16, 477483. http://dx.doi.org/10.1002/gps.366

[60] Voigt, K., Nagel, A., Meyer, B., Langs, G., Braukhaus, C. and Löwe, B. (2010) Towards positive diagnostic criteria: A systematic review of somatoform disorder diagnoses and suggestions for future classification. Journal of Psychosomatic Research, 68, 403-414. http://dx.doi.org/10.1016/j.jpsychores.2010.01.015

[61] Kroenke, K., Spitzer, R., deGruy, F., Hahn, S., Linzer, M. and Williams, J., et al. (1997) Multisomatoform disorder: An alternative to undifferentiated somatoform disorder for the somatizing patient in primary care. Archives of General Psychiatry, 54, 352-358. http://dx.doi.org/10.1001/archpsyc.1997.0183016008001 1

[62] Rief, W., Heuser, J., Mayrhuber, E., Stelzer, I., Hiller, W. and Fichter, M.M. (1996) The classification of multiple somatoform symptoms. Journal of Nervous \& Mental Disease, 184, 680-687. http://dx.doi.org/10.1097/00005053-199611000-00005

[63] Rubio, G. and Lopez-Ibor, J. (2007) Generalized anxiety disorder: A 40-year follow-up study. Acta Psychiatrica Scandinavica, 115, 372-379. http://dx.doi.org/10.1111/j.1600-0447.2006.00896.x

[64] Sheikh, J.I., Swales, P.J., King, R.J., Sazima, G.C. and Bail, G. (1999) Somatization in young versus older female panic disorder patients. International Journal of Geriatric Psychiatry, 13, 564-567. http://dx.doi.org/10.1002/(SICI)1099-1166(199808)13:8< 564::AID-GPS817>3.0.CO;2-4

[65] Drayer, R.A., Mulsant, B.H., Lenze, E.J., Rollman, B.L., Dew, M.A. and Kelleher, K., et al. (2005) Somatic symptoms of depression in elderly patients with medical comorbidities. International Journal of Geriatric Psychiatry, 20, 973-982. http://dx.doi.org/10.1002/gps.1389

[66] Hilderink, P.H., Benraad, C.E.M., van Driel, D., Buitelaar, J.K., Speckens, A.E.M. and Rikkert, M.G.M.O., et al. (2009) Medically unexplained physical symptoms in elderly people: A pilot study of psychiatric geriatric characteristics. The American Journal of Geriatric Psychiatry, 17, 1085-1088. http://dx.doi.org/10.1097/JGP.0b013e3181b975a1

[67] Shahpesandy, H. (2005) Different manifestation of depressive disorder in the elderly. Neuroendocrinology Letters, 26, 691-695. http://www.nel.edu/home.htm.

[68] Yu, D.S.F. and Lee, D.T.F. (2012) Do medically unexplained somatic symptoms predict depression in older Chinese? International Journal of Geriatric Psychiatry, 27, 119-126. http://dx.doi.org/10.1002/gps.2692 